\title{
Prevalence and Risk Factors for Albuminuria among HIV Ivorian Children, Using the Dipstick Method
}

\author{
Tia Weu Melanie ${ }^{1}$, Messou K. Eugene ${ }^{2}$, Lagou Delphine Amelie ${ }^{1}$, Cisse Lassina ${ }^{3}$, \\ Grinmaud Mylene'1, Coulibaly Pessa Albert'1, N'Zoue Kanga Sita1 \\ ${ }^{1}$ Department of Nephrology, CHU Yopougon, Abidjan, Côte d'Ivoire \\ ${ }^{2} \mathrm{CePReF}$, Abidjan, Côte d'Ivoire \\ ${ }^{3}$ Department of Paediatrics, Chu Treichville, Abidjan, Côte d'Ivoire \\ Email:weutia2015@gmail.com,messou_eugene@yahoo.fr, amelilagou@gmail.com, cisselassi@hotmail.fr, \\ mylenegrimaud@yahoo.fr, coulinalyalbert3@yahoo.fr,k.nzoue@yahoo.fr
}

How to cite this paper: Melanie, T.W., Eugene, M.K., Amelie, L.D., Lassina, C., Mylene, G., Albert, C.P. and Sita, N.K. (2018) Prevalence and Risk Factors for Albuminuria among HIV Ivorian Children, Using the Dipstick Method. Open Journal of Nephrology, 8, 1-9.

https://doi.org/10.4236/ojneph.2018.81001

Received: December 6, 2017

Accepted: March 4, 2018

Published: March 7, 2018

Copyright $\odot 2018$ by authors and Scientific Research Publishing Inc. This work is licensed under the Creative Commons Attribution International License (CC BY 4.0).

http://creativecommons.org/licenses/by/4.0/

\section{(c) (i) Open Access}

\begin{abstract}
Context. Human immunodeficiency virus (HIV) infected children are at risk of developing chronic kidney disease defined by decreased glomerular filtration rate and or proteinuria. Studies on the prevalence of and risk factors for proteinuria among HIV-infected children in sub-Saharan Africa are scarce and in Cote d'Ivoire, there is paucity of reported data. We determined the prevalence of and the risk factors for proteinuria among HIV-infected Ivorian children in both ART (antiretroviral therapy)-naïve and ART-exposed children. Method: It was a cross-sectional bi-centric study, conducted from July 2013 to April 2014. Each child's urine was tested for proteinuria and microalbuminuria using multi test strips and mitral test, respectively. Proteinuria was defined as of significant of $1+$ and above on the dipstick or the presence of microalbuminuria $\geq 20$ $\mathrm{mg} / \mathrm{l}$. Results. Of the 155 HIV-infected children enrolled, there were 78 boys. Sixty seven point seven percent were treated with antiretroviral and $74.1 \%$ had treatment duration of less than 5 years. In the first dipstick test, the prevalence of proteinuria was $29 \%$ which persisted in $9.7 \%$ after 24 hour urinary protein examination. It was significantly different between the 2 groups treated and naïve (2.8\% versus $24 \%)$. The advanced CDC clinical stage emerged as the main independent determinant of proteinuria. Conclusion: Proteinuria is common in HIV-infected Ivorian children. Screening for proteinuria in HIV-infected children will help in early and treatment, and thus prevention and progression to chronic kidney disease to end-stage kidney disease.
\end{abstract}

\section{Keywords}

Prevalence, Proteinuria, HIV, Ivorian Child, Antiretroviral Therapy 


\section{Introduction}

Human immunodeficiency virus (HIV) is by far one of the most common pathogen worldwide. In 2015, approximately 3.2 million children were living with HIV worldwide. Most of them lived in low- and middle-income countries, and around two-third lived in sub-Saharan Africa [1]. Cote d'Ivoire's HIV prevalence is one of the highest in West Africa, at the level of 2.7 percent with approximately 29,000 children living with HIV in 2015 . Only $8 \%$ of infected children received appropriate antiretroviral therapy $(A R T)<15$ years of age were receiving treatment [2].

Socio-economic and political factors are, among others, the main factors likely to explain the spread of HIV pediatric HIV in Africa. These factors include limited availability and access to basic healthcare facilities, lack of communication on preventive measures, lack of transportation, and a number of barriers to the implementation of pediatric antiretroviral therapy. Without treatment, approximately half of the infected children will die by the age of two due to opportunistic infections [3]. Fortunately considerable progress has been made towards the elimination of HIV among children with the increase in the antiretroviral therapy coverage. Indeed, the use of the highly active antiretroviral therapy regimen has improved the prognosis of African children infected by HIV. As a result, more children are able to get to the adulthood, making HIV/Aids a chronic disease for what there is a need to pay attention to the complications associated with HIV with the treatment over time.

Kidney disorders are among the ten most common non-communicable conditions occurring in HIV-infected children in the HAART era [4]. The spectrum of kidney diseases reported in these children includes electrolyte disorders, tubular functional abnormalities, and glomerular diseases associated with proteinuria. Proteinuria in patients with glomerular diseases due to HIV ranges from asymptomatic microalbuminuria to nephrotic syndrome. The global burden of kidney disease in pediatric HIV population is hard to estimate but proteinuria is relatively common, and is associated with the increase in the death rate and the hospitalization. The prevalence of proteinuria among HIV-infected children, according to available data, ranges from 21\% [5] to $72 \%$ [6] in Sub-Saharan Africa. Few studies exist on proteinuria in the pediatric HIV African population. However, only scant data is available from Ivory Coast. Our objective was to measure the prevalence of proteinuria and to describe the factors associated with proteinuria in a group of Ivorian HIV-infected children.

\section{Methods}

\subsection{Study Design}

The study was designed as a cross-sectional and descriptive study based on the follow up of HIV-infected children attending two medical centers in Abidjan. The study sites included the "Centre de Traitement Ambulatoire Pédiatrique (CTAP)", which is the Treatment Center for HIV-infected children and located 
within the teaching hospital of Yopougon and the "Centre de Prise en Charge, de Recherche et Formation (CePReF)".

\subsection{Study Population}

The sample size of 155 was calculated by the sampling method used to get an estimate of proportions for study population less than 10,000 in size [7]. The children with no clinical symptoms for HIV/Aids received for routine visits every 6 months were enrolled between July 2013 and April 2014. Prior to enrolling them, children were clinically assessed to ascertain their steady state during the past two weeks prior to their visit to the clinic.

Enrolled Children were less than 15 years; tested positive for HIV, either by the polymerase chain reaction (PCR) for children less than 18 months, or by antibody detection for those older than 18 months; informed consent was required from parents or caregivers before enrolling the children for the study. Patients were excluded if they had the following symptoms: fever (temperature of $38^{\circ} \mathrm{C}$ ) or high blood pressure, if urine samples were positive for nitrite and leukocytes (indicating urinary tract infection).

Also, we did not include children with a personal history of renal failure, diabetes, hepatitis B or C, receiving treatment with angiotensin-converting-enzyme inhibitors or corticosteroid therapy, antiretroviral therapy including Tenofovir or Indinavir as well as female adolescent with menses.

\subsection{Data Collected and Collection Method}

At study entry, caregivers or parents provided demographic information (date of birth, gender, and education level of the child), medical history (HIV status and parents' HIV status, personal history of hypertension, diabetes, Hepatitis B, C, edema, hematuria, renal failure, date of diagnosis of HIV infection, HIV serotype, reasons for hospitalization since the diagnosis of HIV infection), and therapeutic data (date of start of ART, successive treatment regimens of the child and reasons for change, if any). Clinical history and complete physical examination including the measure of the weight, the height and the blood pressure (BP), were performed upon arrival by a physician. The blood pressure was measured using an automated, non-invasive monitor while the children is in sitting position; the mean of at least two measures was standardized by gender, age, and height using methods outlined in the Fourth Report on the Diagnosis, Evaluation, and Treatment of High Blood Pressure in Children and Adolescents [8]. Blood and urine samples were drawn at enrolment for $\mathrm{CD} 4$ count, creatinine and proteinuria.

HIV infected children were asked to get a fresh spot urine sample in a tightly screwed plastic bottle. Spot urine sample was tested for proteinuria by dipstick method (Combur Test Medical, Roche Diagnostics, Germany). Proteinuria was graded as follows: $0,+(30 \mathrm{mg} / \mathrm{dl}),++(100 \mathrm{mg} / \mathrm{dl}),+++(300 \mathrm{mg} / \mathrm{dl})$ and ++++ $(1000 \mathrm{mg} / \mathrm{dl})$. Proteinuria of $(+)$ or more were accepted significant. Patients with proteinuria were reassessed after two days, for timed urine collection. It was 
performed microalbuminuria measured according to the Esbach method on 24-hour urine collection. The microalbuminuria was defined as proteinuria between 30 and $300 \mathrm{mg} / 24 \mathrm{~h}$. When the proteinuria was $\geq 300 \mathrm{mg} / 24 \mathrm{~h}$, it was a macroalbuminuria. The proteinuria was referred to as nephrotic for values $\geq 50$ $\mathrm{mg} / \mathrm{kg} / 24 \mathrm{~h}$.

The creatinine was measured by Jaffe reaction [9]. Estimated glomerular filtration rate (eGFR) was calculated from a single serum creatinine value obtained at enrolment visit using the Bedside Schwartz formula $[\mathrm{k} \times$ height $(\mathrm{cm}) /$ creatinine $(\mathrm{mg} / \mathrm{dL})$ [10]. Chronic kidney disease was classified using the K/DOQI clinical practice guidelines [11]. When the GFR is $\geq 120 \mathrm{~mL} / \mathrm{min}$, it described hyper filtration; between 90 and $120 \mathrm{ml} / \mathrm{min}$, we talk about normal renal function; between 60 and $90 \mathrm{~mL} / \mathrm{min}$, it is defined as a moderate renal failure.

The findings from the clinical assessment and the laboratory tests were used for the clinical and immunological staging of the participants according to the CDC's HIV classification [12]. Advanced HIV disease was defined as stage C, while stage A and B were defined asymptomatic and non advanced HIV disease. Severe immunosupression was defined as CD4 count less than 350 cells $/ \mu \mathrm{L}$ in children aged 5 years and above, and for those below age 5 years a CD4 percentage less than 25.

\subsection{Statistical Analysis}

A statistical software package (SPSS v21) was used for the statistical analysis. Characteristics were described by medians value for continuous variables and frequencies for categorical variables. The comparisons were made using the Student's t-test for quantitative variables and using the $\mathrm{Chi}^{2}$ test for qualitative variables. P-Value less than 0.05 was considered statistically significant. The search for associated factors was carried out using a logistic regression.

\section{Results}

\subsection{Anamnestic Data}

155 HIV-infected children were enrolled for the study. 50 of them never received ART and 105 other have already been exposed to ART. Seventy eight (78/155) children (50.3\%) were male and the sexratio was 1.01 . The children were aged 2 to 15 with a median age of 11 years. Ninety two percent (92.9\%) of the children were enrolled in school. $63 \%$ of mothers were alive.

\subsection{Clinical Data}

46 of all the children, (29.7\%) were at stage A of CDC classification of HIV, 80 (51.6\%) were at stage B and 29 (18.7\%) were at stage C. 12\% of children who never received ART were at stage C, compared to $22 \%$ of children under ART.

\subsection{Biological Data}

37 children (24\%) had a hyperfiltration. This number included 7 children who 
never received ART and 30 children receiving ART. The GFR was normal for the majority of cases (74\%). Three children had mild kidney failure (2\%). Within the entire group of these HIV-infected children, urine dipstick was positive in $29 \%$ of the cases. The prevalence of proteinuria was $23.8 \%$ among children who received ART versus $40 \%$ among those who never received ART ( $\mathrm{p}=0.038)$. Of 45 positive dipstick, only 15 (33\%) had performed the proteinuria over 24 h: 12 among children who never received ART and 3 among those received among those who received ART. Seven (7) children had macroalbuminuria. Two (2) had nephrotic proteinuria and never received ART. The prevalence of proteinuria among all the children was $9.7 \%$. This prevalence was $24 \%$ in the group children not receiving ART and $2.8 \%$ in the group of children under ART. The ART appears to be a determining factor in the occurrence or not of significant proteinuria (Table 1). Of the clinical features, none are predictive of the occurrence of proteinuria (Table 2). By comparing non-proteinuric and non-proteinuric ARV-treated children, it appears that only the clinical stage $\mathrm{C}$ is determinant in the occurrence of proteinuria (Table 3). All were HIV1-positive. The CD4 levels ranged from $1 \%$ to $43 \%$ among children not receiving ART (mean of $21.9 \%$ ) and were between $2 \%$ and $56 \%$ among children under ART (mean of 27\%). The 15 children with 24-hour proteinuria had CD4 count between $9 \%\left(169 / \mathrm{mm}^{3}\right)$ and $31 \%\left(1405 / \mathrm{mm}^{3}\right) .105$ children $(67.7 \%)$ were under ART versus $50(32.3 \%)$ without ART. The most frequently used ART regimen was AZT + 3TC + EFV. This was the case for 78 children, representing $74.2 \%$ of those under ART.

Table 1. Relation between proteinuria and ART therapy.

\begin{tabular}{|c|c|c|c|c|}
\hline Variables & $\begin{array}{l}\text { Children treated } \\
\quad(\mathrm{n}=105)\end{array}$ & $\begin{array}{l}\text { Children not treated } \\
\qquad(\mathrm{n}=50)\end{array}$ & $\begin{array}{l}\text { Total size } \\
(n=155)\end{array}$ & $\mathrm{p}$ \\
\hline Dipstick +, n (\%) & $25(23.8)$ & $20(40)$ & $45(29.03)$ & 0.0380 \\
\hline $24 \mathrm{~h}$ urine collection $\mathrm{n}(\%)$ & $3(2.8)$ & $12(24)$ & $15(9.7)$ & 0.0000 \\
\hline
\end{tabular}

$\mathrm{n}=$ absolute number, $\%=$ percentage.

Table 2. Clinical Characteristics of children studied according to the proteinuria.

\begin{tabular}{|c|c|c|c|c|c|}
\hline Variables & $\begin{array}{l}\text { Dipstick + } \\
(\mathrm{n}=45)\end{array}$ & $\begin{array}{l}\text { Dipstick- } \\
(\mathrm{n}=110)\end{array}$ & $\begin{array}{l}24 \mathrm{~h} \text { urine collection+ } \\
\qquad(\mathrm{n}=15)\end{array}$ & $\begin{array}{l}24 \text { urine collection- } \\
\qquad(\mathrm{n}=140)\end{array}$ & $\mathrm{p}$ \\
\hline Age m (+/-SD) & $10.24(3.2)$ & $10.32(3)$ & $10.5(3.2)$ & $10.3(3.1)$ & 0.87 \\
\hline Sex male, $\mathrm{n}(\%)$ & $22(48.89)$ & $56(50.91)$ & $8(53.3)$ & $70(50)$ & 0.82 \\
\hline Height m (+/-SD) & $134(17.92)$ & $131(17.98)$ & $138(16)$ & $131(18)$ & 0.40 \\
\hline Weight (+/-SD) & $30.2(10.43)$ & $28.2(10.12)$ & $31.4(11.4)$ & $28.5(10.1)$ & 0.27 \\
\hline PAS m (+/-SD) & $103.6(11.1)$ & $101.1(10.2)$ & $102.1(9.5)$ & $101.8(10.6)$ & 0.18 \\
\hline PAD m $(+/-S D)$ & $65.9(9.7)$ & $65.3(9.4)$ & $67.9(10.5)$ & $69.2(9.4)$ & 0.75 \\
\hline
\end{tabular}

$\mathrm{n}=$ absolute number, $\mathrm{m}=$ mean, $\mathrm{SD}=$ standard deviation. 
Table 3. Determinants of proteinuria in HIV children treated and non-treated.

\begin{tabular}{cccc}
\hline Variables & coefficients & $\mathrm{p}$ & OR (IC 95\%) \\
\hline CDC stage C & -1.87 & 0.013 & $0.1538(0.035 / 0.672)$ \\
Severe immunodepression & 0.0714 & 0.926 & $1.0740(0.2383 / 4.8403)$ \\
Age $>$ or $=$ mean & 0.9044 & 0.192 & $2.4704(0.634 / 9.625)$ \\
Sex male & 0.1053 & 0.874 & $1.1111(0.3032 / 4.0706)$ \\
\hline
\end{tabular}

\section{Discussion}

Proteinuria and microalbuminuria were observed in $29 \%$ and $9.7 \%$ of cases, respectively. These urinary biological markers were statistically more frequent in the group not receiving ART compared to those under ART. The prevalence of proteinuria in children not receiving ART was $40 \%$. In contrast to this high prevalence observed in our study, lower prevalence of proteinuria has been reported in cross-sectional studies from Zimbabwe where Dondo [13] found $18 \%$ in a population of 220 children aged 1 to 12 years without ART. In this study, the lab test of proteinuria over 24 hours was carried out twice within one week. Indeed, false positives can be found with the urine strip in case of alkaline urine. The persistence of proteinuria beyond a week in a child reflects that this disorder is permanent. The permanent proteinuria is a predictive marker of chronic renal failure. Microalbuminuria, the early marker of nephropathy associated to HIV was the assessment criterion chosen by several authors in Africa and in the US. The prevalence ranged from $12 \%$ according to work by Eke [14] in Nigeria, to 18\% in research from Ekulu [15] in Democratic Congo, and respectively 20.4\% and 28.8\% in works by Fredick [16] and Mosten [17], both from Tanzania. Dimock [18] from Bethesda in US reported a prevalence of $15 \%$. The differences between the results from studies conducted in Congo, Tanzania and our data could be the result of the small size of the sample used for our study. Eke and we looked for microalbuminuria in small samples (15 patients in France and 50 in Eke), unlike Fredick who 220 HIV-positive children. Others authors report a prevalence of $0 \%$ in populations of more than 300 children [19] [20]. These authors used the technique based on nephrelometry which is a technique with a sensitivity ranging from 90 to $99 \%$. Regardless which endpoint is considered, proteinuria is common in HIV-infected children in the sub-Saharan Africa. Severe immunodepression is recognized as a factor in the development of proteinuria [21]. According to Esezobor et al. [5], 37.9\% of treated or untreated protein children were in severe immune-suppression versus $11.9 \%$ in mean immune-suppression $(\mathrm{p}=0.014)$. The occurrence of microalbuminuria is not related to age. This result is similar to the results reported by Fredrick [16], who observed that microalbuminuria was equally distributed across all age groups, suggesting that, regardless age, there is a continuum of renal features from the microalbuminuria which progresses towards proteinuria. On the other hand, Eke et al. [14] showed that microalbuminuria is more likely to occur in older children. 
In our study, this negative correlation between proteinuria and immunesuppression was probably not observed because of the low number. Nevertheless, there was a significant difference in the percentage of CD4 at the expense of ART-naive children $(21.9 \%$ versus $27 \%, \mathrm{p}<0.001)$. It should be noted that immunodepression is a major criterion for ART. While ART can help prevent renal damage due to HIV, it seems logical that ART-exposed children have less proteinuria. The staging used is the start-up of ART in children.

The direct action of the virus on the podocyte leads to a disorganization of the architecture of the nephron and the loss of structure and function of the glomerulus [22]. Maladaptation to changes in glomerular hemodynamics exerts the greatest effect on factors that initiate and perpetuate renal disease progression. The hemodynamic changes lead to glomerular hyperfiltration, and adaptations occur in response to the decrease in the number of functional nephrons. There is an increase in the glomerular filtration preceding the microalbuminuria [23]. Our study could not establish a correlation between the increase of GFR and the microalbuminuria in children infected with HIV, perhaps because of the low prevalence of microalbuminuria in our population.

Our study has some limitations. No children under the age of 2 were included because during the survey we did not have enough urine even in the diapers to perform the urine test strip reliably. The completion of the 24 -hour proteinuria was only possible in one-third of patients with a positive urine band. Indeed, the sensitivity of the urinary tract can be affected by the urinary concentration [24] and does not detect $20 \%$ of people with renal disease. It appears necessary to carry out the quantitative determination either on 24-hour urine or the ratio of albumin to urine creatinine on urination in all patients at risk of developing renal disease. Some children did not return within 48 hours following the positivity of the urine band, mainly because of a lack of financial resources to cover travel costs for an additional visit to the follow-up center. In practice, the collection of diuresis of the 24 -hour is very random especially in very young children. Since the creatinine levels were not routinely used in Abidjan, it was also not possible to work with the proteinuria/creatinine ratio.

\section{Conclusion}

The overall prevalence of proteinuria in our study was $9.7 \%$. It was significantly higher in ART-naïve children (24\% versus $2.8 \%$ ), and in those with advanced clinical stages. The renal function was normal in $80 \%$ of children. We recommend the systematic search for proteinuria at the time of diagnosis of HIV infection and periodically during the follow-up. If the proteinuria persists for a period of 6 months, an antiretroviral therapy should be initiated without delay regardless of the clinical or immunological stage of the infection. If, despite treatment, the proteinuria does not disappear, the child should be referred to the Pediatric Nephrology Department for histological investigations to determine the nature of the renal lesions in order to administer an etiopathogenic treatment so 
as to avoid rapid development to chronic renal failure. It is important in Côte d'Ivoire to integrate the international recommendations into the national program for the medical care of people living with HIV and to carry out wider studies on kidney-related HIV-related diseases.

\section{Acknowledgements}

We are grateful to Dr Dali Aimé Serge for useful comments the final version of this paper.

\section{Disclosure}

All authors declared no competing interests.

\section{References}

[1] United Nations Children's Emergency Fund (UNICEF) (2015) Children \& AIDS 2015 Statistical Update. United Nations Children's Emergency Fund (UNICEF). Children \& AIDS 2015 Statistical Update. http://www.childrenandaids.org

[2] Koseki1, S. and Bowsky, S. (2015) Health Policy Project and the Ministry of Health of Côte d'Ivoire. Estimating the Cost of HIV Treatment for Adults, Children, and Pregnant Women in Côte d'Ivoire: Final Report. Futures Group, Washington DC. Health Policy Project Accessed 22 September 2017.

[3] McCulloch, M.I. and Ray, P.E. (2008) Kidney Disease in HIV-Positive Children. Seminars in Nephrology, 28, 585-594. https://doi.org/10.1016/j.semnephrol.2008.09.001

[4] Chaparro, A.I., Mitchell, C.D., Abitbol, C.L., Wilkinson, J.D., Baldarrago, G., Lopez, E. and Zilleruelo, G. (2008) Proteinuria in Children Infected with the Human Immunodeficiency Virus. Journal of Pediatrics, 152, 844-849. https://doi.org/10.1016/j.jpeds.2007.11.007

[5] Esezobor, C.I., Iroha, E., Onifade, E., Akinsulie, A.O., Temiye, E.O. and Ezeaka, C. (2010) Prevalence of Proteinuria among HIV-Infected Children Attending a Tertiary Hospital in Lagos, Nigeria. Journal of Tropical Pediatrics, 56, 187-190. https://doi.org/10.1093/tropej/fmp090

[6] Han, T.M., Naicker, S., Ramdial, P.K. and Assounga, G.K. (2006) A Cross-Sectional Study of HIV-Seropositive Patients with Varying Degrees of Proteinuria in South Africa. Kidney International, 69, 2243-2250. https://doi.org/10.1038/sj.ki.5000339

[7] Daniel, W.W. and Cross, C.L. (2005) Estimation. In: Daniel, W.W., Ed., Determination of Sample Size for Estimating Proportion, Biostatistics. A Foundation for Analysis in the Health Sciences, Wiley Dreamtech, India, 183-184.

[8] National High Blood Pressure Education Program Working Group on High Blood Pressure in Children and Adolescents (2004) The Fourth Report on the Diagnosis, Evaluation, and Treatment of High Blood Pressure in Children and Adolescents. Pediatrics, 114, 555-576. https://doi.org/10.1542/peds.114.2.S2.555

[9] Romeo, J. (1975) Evaluation of a Kinetic Method for Creatinine. Lab Medicine, 6, 15-18. https://doi.org/10.1093/labmed/6.8.15

[10] Schwartz, G.J., Haycock, G.B., Edelmann Jr., C.M., et al. (1976) A Simple Estimate of Glomerular Filtration Rate in Children Derived from Body Length and Plasma Creatinine. Pediatrics, 58, 259-263.

[11] National Kidney Foundation (2002) K/DOQI Clinical Practice Guidelines for 
Chronic Kidney Disease: Evaluation, Classification, and Stratification. American Journal of Kidney Diseases, 39, S1-S266.

[12] World Health Organization (2006) Antiretroviral Therapy of HIV Infection in Infants and Children in Resource-Limited Settings: Towards Universal Access: Recommendations for a Public Health Approach. World Health Organization, Geneva, 87-94.

[13] Dondo, V., Mujuru, H.A., Kathoo, K.J., Chirelwa, M. and Mafenedaedza, Z. (2013) Renal Abnormalities among HIV-Infected, Antiretroviral Naive Children, Harare, Zimbabwe: A Cross-Sectional Study. BMC Pediatrics, 13, 75-84. https://doi.org/10.1186/1471-2431-13-75

[14] Eke, F.U., Anochie, I.C., Okpere, A.N., et al. (2010) Microalbuminuria in Children with Human Immunodeficiency Virus (HIV) Infection in Port Harcourt, Nigeria. Nigerian Journal of Medicine, 19, 298-301. https://doi.org/10.4314/njm.v19i3.60214

[15] Ekulu, P.M., Aloni, M.N., Harambat, J., et al. (2016) Microalbuminuria among HIV-Infected Antiretroviral Therapy-Naive Children in the Democratic Republic of Congo. Pediatric Nephrology, 31, 769-772.

[16] Fredrick, F., Francis, J.M., Ruggajo, P.J. and Maro, E.E. (2016) Renal Abnormalities among HIV Infected Children at Muhimbili National Hospital (MNH) - Dar es Salaam, Tanzania. BMC Nephrology, 17, 30-35. https://doi.org/10.1186/s12882-016-0242-6

[17] Mosten, I.K., Hamel, B.C. and Kinabo, G.D. (2015) Prevalence of Persistent Microalbuminuria and Associated Factors among HIV Infected Children Attending a Tertiary Hospital in Northern Tanzania: A Cross Sectional, Analytical Study. Pan African Medical Journal, 20, 251-261. https://doi.org/10.11604/pamj.2015.20.251.5429

[18] Dimock, D., Thomas, V., Cushing, A., Purdy, J.B., Worrell, C., Kopp, J.B., Hazra, R. and Hadigan, C. (2011) Longitudinal Assessment of Metabolic Abnormalities in Adolescents and Young Adults with HIV-Infection Acquired Perinatally or in Early Childhood. Metabolism, 60, 874-880. https://doi.org/10.1016/j.metabol.2010.08.007

[19] Ezeonwu, B.U., Okafor, H.U., Ikefuna, A.N. and Oguonu, T. (2012) Screening for Microalbuminuria in HIV-Positive Children in Enugu. International Journal of Nephrology, 2012, 805834.

[20] Leroy, B., Pressac, M., Bensman, A., Sinnassamy, P. and Courpotin, C. (1992) Renal Status in Human Immunodeficiency Virus Infected Children: A Prospective Study. Proceedings of the International AIDS Conference, Amsterdam, 19-24 July 1992.

[21] Purswani, M.U., Chernoff, M.C., Mitchell, C.D., Seage 3rd, G.R., Zilleruelo, G., Abitbol, C., et al. (2012) Chronic Kidney Disease Associated with Perinatal HIV Infection in Children and Adolescents. Pediatric Nephrology, 27, 9819-9825. https://doi.org/10.1007/s00467-011-2097-1

[22] Schwartz, E.J., Cara, A., Snoeck, H., Ross, M.D., Sunamoto, M., Reiser, J., Mundel, P. and Klotman, P.E. (2002) Human Immunodeficiency Virus-1 Induces Loss of Contact Inhibition in Podocytes. Journal of the American Society of Nephrology, 12, 1677-1684.

[23] Brenner, B.M., Goldszer, R.C. and Hostetter, T.H. (1982) Glomerular Response to Renal Injury. Contributions to Nephrology, 33, 48-66. https://doi.org/10.1159/000407066

[24] Siedner, M.J., Atta, M.G., Lucas, G.M., Perazella, M.A. and Fine, D.M. (2008) Poor Validity of Urine Dipstick as a Screening Tool for Proteinuria in HIV-Positive Patients. Journal of Acquired Immune Deficiency Syndromes, 47, 261-263. https://doi.org/10.1097/QAI.0b013e31815ac4ad 